\title{
METABOLISMO DO LACTATO E AVALIAÇÃO DE DESEMPENHO: DOIS LADOS DO MESMO PROCESSO
}

Julia Pedrosa Furlan

Discente de mestrado do Programa de Pós-Graduação em Ciências Fisiológicas da Universidade Estadual de Maringá (UEM), Brasil.

\section{André Luiz Veronez Depieri}

Graduação em Educação Física pela Universidade Estadual de Maringá (UEM), Brasil.

\section{Maria Montserrat Diaz Pedrosa}

Doutorado em Ciências Biológicas - biologia celular; docente do Departamento de Ciências Fisiológicas da Universidade Estadual de Maringá (UEM), Brasil.

E-mail: mmdpfurlan@uem.br
RESUMO: A mensuração do lactato sanguíneo com determinação do limiar anaeróbio é uma forma simples e difundida de avaliar o desempenho físico. O lactato é o produto final da glicólise anaeróbia, um dos processos geradores de energia no corpo humano, junto com os sistemas dos fosfagênios e aeróbio. A contribuição relativa de cada um deles para as demandas energéticas do músculo esquelético depende do tipo, intensidade e duração do exercício, e o lactato é uma forma de medir essa contribuição. Há intensa transferência de lactato entre tecidos e dentro das células musculares. O propósito desta revisão é interligar esses aspectos em uma estrutura coerente a partir da qual novas hipóteses possam ser exploradas. Foram consultados artigos das bases PubMed e Scielo usando os termos treinamento, performance, lactato e metabolismo e livros de fisiologia. O metabolismo sistêmico de lactato e a variação sanguínea do lactato, registrada em avaliações de desempenho, são aspectos inter-relacionados do mesmo processo fisiológico.

PALAVRAS-CHAVE: Ácido láctico; Metabolismo energético; Desempenho atlético

\section{LACTATE METABOLISM AND PERFORMANCE ASSESSMENT: TWO SIDES OF THE SAME PROCESS}

ABSTRACT: The measuring of blood lactate to determine anaerobic threshold is the commonest method to evaluate physical performance. Lactate is the final product of anaerobic glycolysis, one of the energy -producing processes in the human body, coupled to phosphagenic and aerobic systems. Since relative contribution of each for energy demands of the skeleton muscle depends on the type, intensity and duration of the exercise, lactate measures such contribution. There is intense transfer of lactate among tissues and within muscle cells. This review interlinks the above aspects within a coherent structure so that new hypotheses may be taken. Physiology textbooks and articles from PubMed and Scielo databases were consulted by employing the terms training, performance, lactate and metabolism. Lactate systemic metabolism and lactate blood variation registered in performance assessments are inter-related aspects of the same physiological process.

KEY WORDS: Lactic acid; Energetic metabolism; Athletic performance. 
A produção de energia pelo músculo esquelético é obtida por três sistemas: os sistemas citosólicos de fosfagênios e de glicólise anaeróbia (ambos os oxigênio-independentes) e a glicólise aeróbia (oxigênio-dependente) complementada dentro das mitocôndrias pelo ciclo de Krebs e a fosforilação oxidativa (ADEVA-ANDANY et al., 2014). Cada exercício, especialmente em termos de tipo, intensidade e duração, é mais dependente de um sistema energético do que dos outros, mas hoje está claro que todos eles funcionam simultaneamente: não há limites estritos entre o suprimento de energia por um sistema e outro (CAPUTO et al., 2009).

Naturalmente, o consumo máximo de oxigênio pode ser usado como um parâmetro de avaliação da capacidade aeróbia ou potência de um indivíduo; contudo, as medidas de lactato sanguíneo, um produto "residual" da glicólise anaeróbia, é muito mais fácil e tem alta correlação com desempenho (AZEVEDO ET AL., 2009; BRITO VIEIRA et al., 2014; GOODWIN et al., 2007). Em exercícios de intensidade crescente (por exemplo, testes incrementais), as concentrações sanguíneas de lactato permanecem relativamente estáveis até certo ponto, conhecido como Limiar Anaeróbio (LAn) ou Limiar de Lactato (LL), ou Máxima Fase Estável de Lactato (MFEL). A partir desse ponto, há aumento exponencial no lactato sanguíneo, indicativo de um papel maior da glicólise anaeróbia para a produção de energia dentro do músculo em exercícios de alta intensidade (FAUDE; KINDERMANN; MEYER, 2009). Atualmente, é plenamente aceito que essa maior produção de lactato ocorre em condições completamente aeróbias (BROOKS, 2009).

A fisiologia do lactato é muito complexa, particularmente durante o exercício. Vários tecidos tais como rins, fígado, cérebro e coração e não apenas os músculos em atividade mostram tanto liberação quanto captação de lactato. Além disso, dentro da mesma célula muscular, subcompartimentos intracelulares simultaneamente produzem e consomem lactato. Esses desvios intracelulares e interteciduais são conhecidos como transferências, ou shuttles, de lactato (BROOKS, 2000, 2009; VAN HALL, 2010).

Esta revisão descreve esses três aspectos cruciais da fisiologia do exercício: os processos musculares de produção de energia, a cinética tecidual e sistêmica do lactato e o uso do lactato sanguíneo na avaliação do desempenho. O propósito é tentar criar uma estrutura coerente sobre a qual novos questionamentos e hipóteses podem ser explorados.

\section{DESENVOLVIMENTO}

\subsection{PROCESSOS GERADORES DE ENERGIA NO MÚS- CULO ESQUELÉTICO}

A energia que o corpo humano precisa para colocar os músculos esqueléticos em ação vem da hidrólise das moléculas de adenosina trifosfato (ATP). Essas, por sua vez, são sintetizadas por meio de três processos: o sistema ATP-fosfocreatina (sistema ATP-PC, ou de fosfagênios), glicólise anaeróbia e sistema aeróbio. O sistema ATP-PC e a glicólise anaeróbia são parte do metabolismo anaeróbio; isto é, o oxigênio não precisa estar presente para que a síntese de ATP por esses sistemas ocorra. Além disso, o sistema ATP-PC e a glicólise anaeróbia ocorrem inteiramente fora das mitocôndrias, enquanto o sistema aeróbio ocorre principalmente dentro delas (ADEVA-ANDANY et al., 2013, 2014; FOSS; KETEYIAN, 2000; GUYTON; HALL, 2011; WIDMAIER; RAFF; STRANG, 2006).

A contribuição relativa desses sistemas energéticos para um dado exercício ou atividade muscular vai depender de sua intensidade e duração, porque cada sistema é mais capaz de produzir energia em um tipo diferente de evento ou atividade (CAPUTO et al., 2009).

\subsubsection{Sistema dos Fosfagênios}

O sistema ATP-PC é composto por duas reações citosólicas acopladas, a degradação de fosfocreatina e a síntese de ATP, catalisadas pela enzima creatina cinase. $\mathrm{O}$ ATP torna-se ADP + Pi (fosfato inorgânico) quando o fosfato é hidrolisado para suprir energia para outra molécula, por exemplo, a miosina. Quando o Pi se separa da PC, a energia é liberada em tal quantidade que o ATP pode ser ressintetizado. Em outras palavras, a energia do Pi é transferida da PC para o ADP, regenerando ATP. Em um sentido mais básico, o ATP fornece energia para o múscu- 
lo e a PC regenera o ATP. A produção de ATP pelo sistema dos fosfagênios é muito rápida e independente de oxigênio, mas é limitada pelos estoques musculares de PC, relativamente pequenos comparados com a alta demanda energética que um músculo ativo pode ter (FOSS; KETEYIAN, 2000; GUYTON; HALL, 2011; WIDMAIER; RAFF; STRANG, 2006).

\subsubsection{Glicólise Anaeróbia}

Todos os carboidratos ingeridos são degradados a uma molécula mais simples: glicose. Essa pode ser imediatamente oxidada pela glicólise, armazenada no fígado ou no músculo esquelético como glicogênio, ou convertida a triglicerídeos no fígado para ser armazenada no tecido adiposo (FOSS; KETEYIAN, 2000; GUYTON; HALL, 2011; WIDMAIER; RAFF; STRANG, 2006).

A glicólise é o processo pelo qual os carboidratos - glicogênio no músculo e fígado, ou glicose da corrente sanguínea - são degradados para sintetizar ATP. O produto final da glicólise é o piruvato, e esse pode ser ou convertido a lactato na glicólise anaeróbia ou transportado para as mitocôndrias para ser completamente oxidado pelo sistema aeróbio de produção de energia (FOSS; KETEYIAN, 2000; GUYTON; HALL, 2011; WIDMAIER; RAFF; STRANG, 2006).

Na glicólise anaeróbia, a síntese de ATP acontece no citosol da célula muscular. A fonte de energia vem do processo de hidrólise da glicose a lactato. As reações químicas que representam essa via podem ser resumidas da seguinte maneira:

Glicose +2 Pi +2 ADP $=>2$ lactato +2 ATP

Como essa reação mostra, a glicólise anaeróbia é capaz de sintetizar apenas dois moles de ATP por mol de glicose. Na realidade, quatro moles de ATP são produzidos, mas ao longo da via dois moles são "investidos" (i.e, consumidos), de maneira que apenas dois moles são efetivamente produzidos (FOSS; KETEYIAN, 2000; GUYTON; HALL, 2011; WIDMAIER; RAFF; STRANG, 2006).

A reação-chave da glicólise anaeróbia é a redução do piruvato a lactato, catalisada pela enzima lactato desidrogenase (LDH). Ela tem a capacidade de catalisar a reação piruvato/lactato em ambas as direções, dependendo da condição prevalecente na célula (AZEVEDO et al., 2009; BENETTI; SANTOS; CARVALHO, 2000; VAN HALL, 2010). No músculo ativo, a reação é direcionada para a formação de lactato pelo acúmulo de piruvato e NADH no citosol (VAN HALL, 2010). A importância da reação da $\mathrm{LDH}$ é que ela restaura os equivalentes redutores $\left(\mathrm{NAD}^{+}\right)$ que foram consumidos em estágios anteriores da via glicolítica, permitindo então que a produção de energia continue.

Embora o rendimento energético da glicólise anaeróbia seja baixo (grande parte da energia disponível na glicose ainda está presente no produto final, lactato), a produção de energia pelo metabolismo anaeróbio permite aos tecidos responder rapidamente a aumentos na demanda energética, sem limitações tais como suprimento de oxigênio, NADH e piruvato para a célula e as mitocôndrias (VAN HALL, 2010).

\subsubsection{Sistema Aeróbio}

O sistema energético aeróbio depende do uso de oxigênio pelas células. Esse sistema tem três estágios, glicólise aeróbia, ciclo de Krebs e fosforilação oxidativa. É o maior suprimento de ATP durante o repouso e o exercício de baixa intensidade, usando principalmente carboidratos e lipídeos como substratos (FOSS; KETEYIAN, 2000; GUYTON; HALL, 2011; RIVERA-BROWN; FRONTERA, 2012; WIDMAIER; RAFF; STRANG, 2006).

A glicólise aeróbia é a via bioquímica pela qual a glicose é transformada em piruvato, que é então convertido a acetil-CoA dentro das mitocôndrias pelo complexo da piruvato desidrogenase (PDH), em vez de ser convertido a lactato no citosol.

A glicólise aeróbia é completada nas mitocôndrias quando o acetil-CoA é oxidado a dióxido de carbono e água no ciclo de Krebs. Os prótons liberados nesse ciclo são transferidos, acoplados a $\mathrm{NAD}^{+}$e FAD (NADH e $\mathrm{FADH}_{2}$ sendo suas formas reduzidas), para a cadeia mitocondrial de transporte de elétrons, que culmina no terceiro estágio do sistema aeróbio, a fosforilação oxidativa do ADP a ATP, com os elétrons e prótons sendo transferidos para o oxigênio. Nesse caso, a produção de ATP é mais lenta, mas pode durar mais tempo e ser mais 
produtiva energeticamente. $\mathrm{O}$ rendimento energético de um único NADH é de três moles de ATP, e o de um $\mathrm{FADH}_{2}$ é de dois (FOSS; KETEYIAN, 2000; GUYTON; HALL, 2011; WIDMAIER; RAFF; STRANG, 2006).

Somando os ATPs produzidos pelo sistema aeróbio, há 38-39 moles de ATP sintetizados para cada mol de glicose.

Além da glicose, ácidos graxos podem ser usados pelo sistema aeróbio. Os ácidos graxos são oxidados dentro das mitocôndrias por uma via denominada beta -oxidação, resultando na formação de muitos moles de acetil-CoA, o número exato dependendo do ácido graxo que está sendo oxidado. O acetil-CoA entra no ciclo de Krebs e é oxidado como descrito anteriormente (FOSS; KETEYIAN, 2000; GUYTON; HALL, 2011; WIDMAIER; RAFF; STRANG, 2006).

Durante a transição inicial do repouso para 0 exercício, o músculo esquelético exibe alta taxa de glicólise anaeróbia. Isso se deve a um aumento instantâneo na demanda por ATP no início do exercício, enquanto a captação e o uso muscular de oxigênio estão atrasados, especialmente por causa do intervalo de tempo para o aumento da perfusão sanguínea muscular. Como o nível de ATP muscular não muda, a síntese deve ocorrer por mecanismos anaeróbios: fosfagênios e glicólise anaeróbia (RIVERA-BROWN; FRONTERA, 2012; VAN HALL, 2010). Juntos, esses dois processos são cruciais para fornecer energia enquanto o sistema aeróbio (glicólise aeróbia, ciclo de Krebs e fosforilação oxidativa) ainda não está plenamente ativo. Conforme o tempo passa e a intensidade do exercício é mantida, o sistema aeróbio torna-se o principal responsável pelo suprimento de energia; nesse ponto a produção de lactato se reduz, porque a taxa de glicólise anaeróbia também está reduzida, já que o piruvato é desviado da LDH para o complexo da PDH (VAN HALL, 2010).

Quando a intensidade do exercício aumenta, tal como durante um teste incremental, ocorre novamente desequilíbrio na produção de energia, e o sistema glicolítico anaeróbio é o responsável pela geração da energia adicional, de modo que há aumento exponencial na concentração sanguínea de lactato (BENETTI; SANTOS; CARVALHO, 2000; VAN HALL, 2010).

\subsection{METABOLISMO DO LACTATO PELOS TECIDOS}

Todos os tecidos parecem ter alta capacidade de transporte lactato, tanto de captação quanto de liberação. Dentro dos limites das concentrações fisiológicas de lactato, a captação desse metabólito parece depender do gradiente de concentração entre os fluidos extra- e intracelular. Nesse sentido, o lactato é mais vantajoso do que a glicose, cujo transporte é insulina-dependente em muitas células, como adipócitos e células musculares esqueléticas (que representam grande parte da massa corporal), especialmente no repouso (GUYTON; HALL, 2011; WIDMAIER; RAFF; STRANG, 2006). Portanto, o lactato pode ter propriedades que o tornam interessante como fonte de energia em certas situações, até mesmo preferível à glicose, além de promover um significativo reaproveitamento de energia.

No nível sistêmico, vários tecidos usam lactato como fonte energética durante o repouso e o exercício. O coração, por exemplo, usa cerca de $20 \mathrm{mmol} \times \min ^{-1}$ de lactato durante o repouso e até $80 \mathrm{mmol} \times \mathrm{min}^{-1}$ no exercício. A contribuição da oxidação do lactato para a produção de energia do coração é cerca de 10-15\% no repouso, aumentando para até 30\% durante o exercício; essa contribuição é mais significativa do que a da glicose exógena, que varia de $8 \%$ a $14 \%$ no repouso e no exercício, respectivamente (VAN HALL, 2010). Durante o exercício, o miocárdio também consome mais lactato do que ácidos graxos, seu principal combustível no repouso (BROOKS, 2000, 2009).

O cérebro contribui substancialmente para a produção (13\%) e uso (8\%) sistêmicos de lactato no repouso. Durante o exercício, o uso de lactato por neurônios e astrócitos aumenta para até $11 \%$. A oxidação de lactato nos tecidos cerebrais representa cerca de $7 \%$ do consumo energético desse tecido em repouso, e até $25 \%$ durante 0 exercício (VAN HALL, 2010).

Os rins e o fígado têm importante papel na remoção do lactato da corrente sanguínea. O papel do lactato nesses órgãos é ser uma fonte principal de carbono para a gliconeogênese, processo pelo qual moléculas como lactato, glicerol e aminoácidos são convertidas a glicose (BROOKS, 2000, 2009; GUYTON; HALL, 2011; WIDMAIER; RAFF; STRANG, 2006). O lactato captado pelos rins é substrato de mais da metade da gliconeogênese 
renal. Ainda não está claro como esse processo é modificado nos rins pelo exercício, mas especula-se que a captação renal de lactato aumenta (VAN HALL, 2010).

No fígado, a remoção de lactato varia de 200 mmol $\times \mathrm{min}^{-1}$ no repouso para $400 \mathrm{mmol} \times \mathrm{min}^{-1}$ durante o exercício (VAN HALL, 2010). No clássico ciclo de Cori, o lactato sanguíneo é reconvertido a glicose, que pode ser liberada pelo fígado para a circulação para ser usado novamente como substrato energético ou armazenada como glicogênio no próprio fígado (ADEVA-ANDANY ET AL., 2014; GUYTON; HALL, 2011; WIDMAIER; RAFF; STRANG, 2006). A gliconeogênese a partir de lactato no fígado aumenta de $18 \%$ durante o estado pós-absortivo no repouso para 25\% durante o exercício (BENETTI; SANTOS; CARVALHO, 2000).

Nos eritrócitos, a produção de energia ocorre somente por glicólise anaeróbia com produção de lactato, uma vez que essas células não têm a maquinaria mitocondrial necessária para a oxidação complexa (oxigênio-dependente) da glicose pelo metabolismo aeróbio (ADEVA-ANDANY et al., 2014). A produção de lactato pelos eritrócitos pode representar uma fração significativa da produção total de lactato no repouso.

O músculo esquelético é uma fonte importante do lactato encontrado na corrente sanguínea, especialmente durante o exercício. Contudo, ele também é um consumidor de lactato, mesmo em condições completamente aeróbias. Durante o exercício contínuo progressivo, o músculo ativo é o local de produção de lactato e sua liberação na corrente sanguínea (BROOKS, 2000, 2009). A oxidação é a rota mais provável de remoção de lactato pelo músculo esquelético; conforme a taxa metabólica aumenta durante o exercício, a oxidação de lactato pelo músculo também aumenta (BROOKS, 2000, 2009; GOODWIN et al., 2007).

Dois outros tecidos que podem contribuir para a remoção e produção de lactato são os pulmões e as vísceras abdominais, embora as quantidades e os processos pelos quais isso ocorre ainda não estejam claros (VAN HALL, 2010).

Em geral, portanto, o aumento no lactato sanguíneo aumenta a captação de lactato pelo cérebro, músculos, miocárdio, fígado e rins (ADEVA-ANDANY et al., 2014), criando transferência ou shuttle, inter-tecidual de lactato (BROOKS, 2000). A grande vantagem da oxidação direta do lactato pelos tecidos é que a glicose e o glicogênio não são gastos no processo de glicogenólise/glicólise para gerar energia de maneira rápida, mas de baixo rendimento. Em vez disso, os tecidos fazem uso do lactato, disponível em grandes quantidades na corrente sanguínea, e o oxidam diretamente, sem ele ser transformado de volta a glicose nos rins ou no fígado (VAN HALL, 2010).

Para explicar como o músculo esquelético é capaz de produzir e consumir lactato, e como esses dois processos podem acontecer simultaneamente durante a contração muscular, foi proposto o modelo de compartimentalização miocelular. Esse modelo sugere que o uso e a produção de lactato acontecem dentro da mesma célula, mas em subcompartimentos citosólicos distintos. Um compartimento glicolítico, localizado próximo às miofibrilas e aos estoques de glicogênio, está associado com glicogenólise/glicólise e produção de lactato. E um segundo compartimento, denominado oxidativo, localizado próximo às mitocôndrias, está associado com captação e oxidação de lactato. Fica estabelecido então um shuttle intracelular de lactato (VAN HALL, 2010). Isoformas de $\mathrm{LDH}$ e de transportadores de lactato foram encontrados nas mitocôndrias musculares (BROOKS, 2000, 2009). Igualmente, transportadores de lactato na membrana plasmática muscular, denominados MCT1, promovem o fluxo de lactato para dentro e para fora das células musculares. Em resumo, esses transportadores permitem o efluxo de lactato das fibras musculares ativas, especialmente as glicolíticas - em que a produção de energia é principalmente anaeróbia e resulta na produção de lactato - e sua captação pelas fibras musculares oxidativas, fígado e rins, em que o lactato é usado como descrito anteriormente (BROOKS, 2000, 2009). O aumento de temperatura e a redução do $\mathrm{pH}$ locais, comuns em músculos sob intensa atividade contrátil, acentuam a liberação de lactato pela membrana sarcoplasmática (BENETTI; SANTOS; CARVALHO, 2000).

O treinamento físico tem efeitos significativos sobre o metabolismo sistêmico de lactato e, portanto, sobre seus níveis sanguíneos em diferentes intensidades de exercício. Especialmente, parece que o treinamento físico aumenta a capacidade de captação de lactato sem alterar sua produção (BENETTI; SANTOS; CARVALHO, 2000). Os 
efeitos do treinamento incluem capacidade oxidativa geral aumentada e mudanças na densidade de transportadores de lactato (ADEVA-ANDANY et al., 2014; BERTUZZI et al., 2011; BRITO VIEIRA et al., 2014; BROOKS, 2000). O nível de estoques de glicogênio, a composição das fibras musculares, as atividades de enzimas glicolíticas e lipolíticas, a densidade capilar e mitocondrial do músculo, e a capacidade gliconeogênica são também fatores modificáveis pelo treinamento que irão afetar os níveis sistêmicos de lactato (BENETTI; SANTOS; CARVALHO, 2000; FAUDE; KINDERMANN; MEYER, 2009).

\subsection{O LACTATO NAS AVALIAÇÕES DE DESEMPENHO}

A avaliação do desempenho em indivíduos ativos e atletas é importante para a prescrição de protocolos de exercício e treinamento. $\mathrm{O}$ registro do lactato sanguíneo e sua cinética durante o teste são ferramentas importantes para essa avaliação. A resistência de um indivíduo ao exercício está mais fortemente correlacionada com a resposta do lactato sanguíneo ao exercício submáximo do que com o consumo máximo de oxigênio $\left(\mathrm{VO}_{2 \max }\right)(\mathrm{GOO}$ DWIN et al., 2007; JACOBS; SJÖDIN, 1985). Frequentemente, testes incrementais são empregados para avaliar a capacidade do desempenho aeróbio pelo registro do lactato sanguíneo (FAUDE; KINDERMANN; MEYER, 2009).

Embora diferentes metodologias tenham sido empregadas para a identificação dos índices associados com a resposta do lactato sanguíneo durante exercício submáximo, basicamente duas intensidades de exercício foram determinadas em testes incrementais (CAPUTO ET AL., 2009; FAUDE; KINDERMANN; MEYER, 2009):

1) Limiar aeróbio: intensidade imediatamente antes do aumento do lactato sanguíneo em relação aos valores de repouso durante um teste incremental. É o limite superior de metabolismo quase exclusivamente aeróbio, que pode ser prolongado por horas.

2) Limiar anaeróbio (LAn) ou Limiar de lactato (LL): intensidade de exercício mais alta em que o lactato liberado na corrente sanguínea pelos músculos é semelhante à taxa com que é removido do sangue, existindo ainda equi- líbrio na concentração de lactato durante o teste. Esse limiar pode ser observado em um gráfico de intensidade do exercício $v s$ concentração de lactato como o ponto em que há mudança abrupta na inclinação da curva de lactato. Com intensidades de exercício progressivamente mais altas, a concentração sanguínea de lactato aumenta exponencialmente (BENETTI; SANTOS; CARVALHO, 2000; GOODWIN et al., 2007; VOLTARELLI; GOBATTO; MELLO, 2002).

Contudo, existe grande variabilidade nesses termos, bem como nos protocolos de exercício usados para sua construção e nos métodos empregados para sua identificação. Faude; Kindermann; Meyer (2009) apresentam discussão detalhada desse assunto.

O "padrão ouro" para a determinação do LAn é a Máxima Fase Estável de Lactato (MFEL). O protocolo é realizado com vários testes de carga constante durando 30 minutos cada um. O MFEL é a máxima intensidade em que há diferença não superior a $1 \mathrm{mmol} \cdot \mathrm{L}^{-1}(1 \mathrm{mM})$ na concentração de lactato entre o décimo e o $30^{\circ}$ minuto do teste (AZEVEDO et al., 2009; HECK et al., 1985).

Outro método usado para estimar a intensidade que corresponde ao equilíbrio entre produção e remoção de lactato é a inspeção visual. Esse é um método simples, em que dois investigadores experientes identificam o LAn como sendo o aumento abrupto não linear na concentração de lactato em um gráfico de intensidade de exercício $v s$ concentração de lactato em um teste incremental (FAUDE; KINDERMANN; MEYER, 2009; WASSERMAN, 1967).

O uso do método de concentração fixa (OBLA, a sigla em inglês para "início do acúmulo do lactato sanguíneo") também é muito popular. A partir de testes incrementais, o LAn é determinado como o valor fixo de 4,0 mM, e a partir da interpolação linear na curva de lactato é identificada a intensidade de exercício que corresponde a essa concentração (GOODWIN et al., 2007; HECK et al., 1985). Entretanto, esse método tem sido questionado, por causa da grande variação entre indivíduos nas concentrações de lactato que correspondem ao LAn, entre 1,4 e 7,5 mM (GOODWIN et al., 2007; STEGMANN; KINDERMANN; SCHNABEL, 1981). 
No método do desvio máximo (Dmax), o LAn é a intensidade de exercício que corresponde ao ponto da curva de lactato mais distante de uma linha reta que conecta o primeiro e o último ponto da curva (MACHADO et al., 2013).

O LAn e a MFEL variam consideravelmente entre indivíduos, tanto em função do padrão motor do exercício quanto, e principalmente, por causa do nível de treinamento do indivíduo (AZEVEDO et al., 2009; FAUDE; KINDERMANN; MEYER, 2009).

\subsection{INTER-RELAÇÃO ENTRE METABOLISMO DE LACTA- TO E LIMIAR ANAERÓBIO}

Um ponto crucial na discussão precedente é a inter-relação entre o perfil de lactato sanguíneo durante os testes de desempenho e a explicação fisiológica/metabólica para as mudanças observadas. Em resumo, o perfil do lactato sanguíneo durante um teste incremental e os fatos conhecidos sobre a cinética sistêmica do lactato podem ser conciliados como segue.

No início do exercício, a glicólise anaeróbia é a responsável primária pelo fornecimento rápido e imediato de energia para a contração muscular, e o lactato sobe acima dos valores de repouso, o que é claramente visível nos minutos iniciais dos testes de MFEL.

Conforme a intensidade do exercício aumenta gradualmente, a contribuição aeróbia para a produção energética muscular também. A produção muscular de lactato cresce, mas é correspondida por captação por outros músculos e tecidos, que podem oxidar lactato (coração, cérebro, músculos) ou convertê-lo a glicose (fígado, rins) e o fazem em proporções maiores durante o exercício do que no repouso. Portanto, o lactato sanguíneo não muda acentuadamente.

O LAn se estabelece quando o desequilíbrio aumenta entre consumo de ATP pelos músculos ativos e produção de ATP pelo sistema aeróbio, demandando participação maior da glicólise anaeróbia. Independente de variações individuais ou induzidas por treinamento, $o$ LAn invariavelmente aparece. Azevedo et al. (2009) propõem que conforme a intensidade do exercício aumenta, o recrutamento de fibras glicolíticas (que têm uma isoforma mais ativa de LDH e maior atividade ATPase) resulta na liberação crescente de lactato, possivelmente superando a capacidade de captação/oxidação dos outros tecidos.

\section{CONSIDERAÇÕES FINAIS}

Analisado do ponto de vista fisiológico sistêmico, o LAn emerge quando o consumo de ATP e sua síntese aeróbia estão aumentando, embora de maneira não correspondente, resultando em maior produção de lactato e seu aumento na corrente sanguínea. Sendo assim, a relação entre esses dois aspectos do lactato - seu metabolismo e sua cinética no sangue - fica evidente, e esclarece fisiologicamente o aparecimento do LAn.

Nesse sentido, é interessante observar que no fígado, um órgão essencial para a reutilização de lactato sanguíneo como fonte de energia (por meio da gliconeogênese), a produção de glicose a partir de lactato aumenta rapidamente para concentrações de lactato entre 0,5 e $4 \mathrm{mM}$, mas tende a se estabilizar entre 4 e 16 mM (SANTIAGO et al., 2013). Sendo assim, a capacidade gliconeogênica hepática, a partir de lactato, poderia ter papel importante no estabelecimento do LAn e na sua alteração com o treinamento. Isso vem de encontro aos relatos de Thyfault; Morris (2017) sobre o papel importante, porém subestimado, do fígado no exercício e nas diferenças de aptidão física em roedores. Certamente, outros mecanismos hepáticos e extra-hepáticos cooperam para o aparecimento do limiar anaeróbio, e devem incluir aspectos moleculares, celulares, bioenergéticos e sistêmicos da fisiologia do lactato.

\section{AGRADECIMENTOS}

Os autores agradecem ao Dr. Danilo Fernandes da Silva e Dra. Cecília Segabinazi Peserico, por seus comentários e sugestões. 


\section{REFERÊNCIAS}

ADEVA-ANDANY, M.; GONZÁLEZ-LUCÁN, M.; SECO, M.; DONAPETRY, C. Enzymes involved in 1-lactate metabolism in humans. Mitochondrion, v. 13, p. 615-629, 2013. DOI: $10.1016 /$ j.mito.2013.08.011

ADEVA-ANDANY, M.; LÓPEZ-OJÉN, M.; FUNCASTA-CALDERÓN, R.; AMENEIROS-RODRÍGUEZ, E.; DONAPETRYGARCÍA, C.; VILA-ALTESOR, M.; RODRÍGUEZ-SEIJAS, J. Comprehensive review on lactate metabolism in human health. Mitochondrion, v. 17, p. 76-100, 2014. DOI: 10.1016/j.mito.2014.05.007

AZEVEDO, P. H. S. M.; GARCIA, A.; DUARTE, J. M. P.; RISSATO, G. M.; CARRARA, V. K. P.; MARSON, R. A. Limiar anaeróbio e bioenergética: uma abordagem didática e integrada. Rev Educ Fís UEM, Maringá, v. 20, n.3, p. 453-464, 2009. DOI: 10.4025/reveducfis.v20i3.4743

BENETTI, M.; SANTOS, R. T.; CARVALHO, T. Cinética de lactato em diferentes intensidades de exercícios e concentrações de oxigênio. Rev Bras Med Esporte, v. 6, n. 2, p. 50-56, mar./abr. 2000. DOI: 10.1590/\$151786922000000200004

BERTUZZI, R. C. M.; LIMA-SILVA, A.; ABAD, C. C. C.; PIRES, F. O. Metabolismo do lactato: uma revisão sobre a bioenergética e a fadiga muscular. Rev. Bras. Cineantropom. Desempenho Hum, v. 11, n. 2, p. 226-234, 2011. DOI: $10.5007 / 1980-0037.2009 v 11 n 2 p 226$

BRITO VIEIRA, W. H.; HALSBERGHE, M. J. E.; SCHWANTES, M. L. B.; PEREZ, S. E. A.; BALDISSERA, V.; PRESTES, J.;FARIAS, D. L.;PARIZOTTO, N. A. Increased lactate threshold after five weeks of treadmill aerobic training in rats. Braz J Biol, v. 74, n. 2, p. 444-449, 2014.DOI: $10.1590 / 1519-6984.07912$

BROOKS, G. A. Intra- and extra-cellular lactate shuttles. Med Sci Sports Exerc, v. 32, n. 4, p. 790-799, 2000.

BROOKS, G. A. Cell-cell and intracellular lactate shuttles. J Physiol., v. 587, n. 23, p. 5591-5600., out. 2009.DOI: 10.1113/jphysiol.2009.178350

CAPUTO, F.; DE OLIVEIRA, M. F. M.; GRECO, C. C.; DENADAI, B. S. Exercício aeróbio: Aspectos bioenergéticos, ajustes fisiológicos, fadiga e índices de desempenho. Rev. Bras. Cineantropom. Desempenho Hum v. 11, n. 1, p. 94-102, 2009. DOI: 10.5007/1980-0037.2009v11n1p94

FAUDE, O.; KINDERMANN, W.; MEYER, T. Lactate threshold concepts: How valid are they? Sports Med., v. 39, n. 6, p. 469-490, 2009. DOI: 10.2165/00007256200939060-00003

FOSS, M. L.; KETEYIAN, S. J. Bases fisiológicas do exercício e do esporte. 6. ed. Rio de Janeiro: Guanabara Koogan, 2000.

GOODWIN, M. L.; HARRIS, J. E.; HERNÁNDEZ, A.; GLADDEN, L. B. Blood lactate measurements and analysis during exercise: a guide for clinicians. J Diabetes Sci Technol, v. 1, n. 4, p. 558-569, jul. 2007. DOI: $10.1177 / 193229680700100414$

GUYTON, A. C.; HALL, J. E. Tratado de fisiologia médica. 11. ed. Rio de Janeiro: Guanabara Koogan, 2011.

HECK, H.; MADER, A.; HESS, G.; MÜCKE, S.; MÜLLER, R.; HOLIMANN, W. Justification of the $4 \mathrm{mmol} / 1$ lactate threshold. Int J Sports Med., v. 6, n. 3, p. 117-130, 1985. DOI: $10.1055 / \mathrm{s}-2008-1025824$

JACOBS, I.; SJÖDIN, B. Relationship of ergometer-specific VO2 max and muscle enzymes to blood lactate during submaximal exercise. Br J Sports Med, v. 19, n. 2, p. 77-80, 1985. DOI: 10.1136/bjsm.19.2.77

MACHADO, F. A.; KRAVCHYCHYN, A. C. P.; PESERICO, C. S.; DA SILVA, D. F.; MEZZAROBA, P. V. Effect of stage duration on maximal heart rate and post-exercise blood lactate concentration during incremental treadmill tests. J Sci Med Sport., v. 16, n. 3, p. 276-280, 2013. DOI: 10.1016/j.jsams.2012.08.003

RIVERA-BROWN, A. M.; FRONTERA, W. R. Principles of exercise physiology: responses to acute exercise and long-term adaptations to training. Phys Med Rehabil , v. 4, p. 797-804, nov. 2012. DOI: 10.1016/j.pmrj.2012.10.007

SANTIAGO, A. N.; GODOI-GAZOLA, V. A. F.; MILANI, M. F.; CAMPOS, V. C.; VILELA, V. R.; PEDROSA, M. M. D.; BAZOTTE, R. B. Oral glutamine is superior than oral glucose 
to promote glycemia recovery in mice submitted to insulin-induced hypoglycemia. Int J Endocrinol, v. 2013, p. 1-7, 2013.DOI: $10.1155 / 2013 / 841514$

STEGMANN, H.; KINDERMANN, W.; SCHNABEL, A. Lactate kinetics and individual anaerobic threshold. Int J Sports Med, v. 2, n. 3, p. 160-165, 1981. DOI: 10.1055/s2008-1034604

THYFAULT, J. P.; MORRIS, E. M. Intrinsic (genetic) aerobic fitness impacts susceptibility for metabolic disease. Exerc Sport Sci Rev, v. 45, n. 1, p. 7-15, jan. 2017. DOI: 10.1249/JES.0000000000000087

VAN HALL, G. Lactate kinetics in human tissues at rest and during exercise. Acta Physiol, v. 199, n. 4, p. 499-508, 2010. DOI: $10.1111 /$ j.1748-1716.2010.02122.x

VOLTARELLI, F. A.; GOBATTO, C. A.; MELLO, M. A. R. Determination of anaerobic threshold in rats using the lactate minimum test. Braz J Med Biol Res, v. 35, p. 13891394, 2002. DOI: 10.1590/S0100-879X2002001100018

WASSERMAN, K. Lactate and related acid base and blood gas changes during constant load and graded exercise. Can Med Assoc J., v. 96, n. 12, p. 775-783, mar. 1967.

WIDMAIER, E. P.; RAFF, H.; STRANG, K. T.Fisiologia humana: os mecanismos das Funções Corporais. 9. ed. Rio de Janeiro: Guanabara Koogan, 2006.

Recebido em: 12 de setembro de 2016 Aceito em: 24 de março de 2017 